\section{Duration discrimination of brief light flashes*}

\author{
LORRAINE G. ALLAN, A. B. KRISTOFFERSON, and E. W. WIENS \\ McMaster University, Hamilton, Ontario, Canada
}

The data from four experiments indicate that when Os discriminate between light flashes of different durations, for durations for which Bloch's law has been shown to hold, their discriminations are frequently made on the temporal information available in the flashes rather than on their apparent brightness. A model for duration discrimination which specifies that discriminability depends only on the difference in duration between the two brief flashes, and is independent of their durations, is presented and applied to the data.

Data from a number of psychophysical investigations (e.g., Aiba \& Stevens, 1964; Raab, 1962; Stevens \& Hall, 1966; Stevens, 1966) have indicated that an O's judgment of the apparent brightness of a brief flash of light depends not only on the luminance of the flash but also on its duration. Specifically, for stimuli whose durations are less than a critical duration, $\mathrm{d}_{\mathrm{c}}$, Os tend to label a brief intense flash of light as equal in apparent brightness to a longer, less intense flash. Furthermore, the data suggest that the relationship between luminance and duration is a reciprocal one, so that the apparent brightness of a flash does not change as long as the product of the flash luminance and the flash duration is constant. That is,

$$
B=f(d \times I),
$$

where $B$ represents the apparent brightness of the flash, $d$ its duration, I its luminance, and

$$
\mathrm{d}<\mathrm{d}_{\mathrm{c}}
$$

The reciprocity relationship in Eq. 1 is often referred to as Bloch's law or the Bunsen-Roscoe law. The exact value of $d_{c}$ depends upon the luminance of the flash and appears to decrease as a power function of luminance (Anglin \& Mansfield, 1968). Thus, within the critical duration for which Bloch's law has been shown to hold, the visual system appears to summate or integrate the light input without regard to its distribution in time. Wicke, Donchin, and Lindsley (1964) have presented physiological data which supplement the psychophysical

*This research was supported by Grants APA-0112 and APA-0175 from the National Research Council of Canada and by Grant NGR-52-059-001 from the National Aeronautics and Space Administration. The authors wish to thank Dr. Stephan W. Link for his many helpful comments. the waveform and the amplitude of the average evoked potentials for a constant luminance-duration product showed a striking similarity for different values of duration.

Since changes in the duration of a brief visual flash result in changes in the apparent brightness of the flash, it is possible that when Os are asked to discriminate between brief light flashes of different durations, their discriminations are based on the apparent brightness of the various flashes rather than on their durations. Suppose that on each trial of a discrimination experiment a light is flashed for either $\mathrm{d}_{0}$ msec, an $S_{0}$ stimulus, or for $\mathrm{d}_{1}$ msec, an $S_{1}$ stimulus, and that the O's task is to decide whether the flash duration was "short," an $A_{0}$ response, or "long," an $A_{1}$ response. If the $\mathrm{O}$ is basing his discrimination on the difference in apparent brightness between $S_{0}$ and $S_{1}$, then decreasing the luminance of $S_{1}$ should result in decreased discriminability. However, if he is basing his discrimination on the difference in duration between the two stimuli, a decrease in the luminance of $S_{1}$ should not affect the discriminability of the two stimuli.

Creelman (1962) has developed a decision theory model which represents the $O$ in a duration discrimination task as using only the temporal information available in the two stimuli to be discriminated. The model pictures the $\mathrm{O}$ as using a mechanism which "counts" pulses during the duration to be judged. The source of pulses which are counted is viewed as a large number of independent elements, each with a fixed probability of firing at any given moment. The basis for the O's decision is the number of pulses which the counting mechanism receives during the duration to be judged. It can be shown that the probability of $n$ counts, $P(n)$, occurring in $d_{i}$ msec is

$$
\mathrm{P}(\mathrm{n})=\frac{\left(\lambda \mathrm{d}_{\mathrm{i}}\right)^{\mathrm{n} \mathrm{e}^{-\lambda \mathrm{d}_{\mathrm{i}}}}}{\mathrm{n} !},
$$

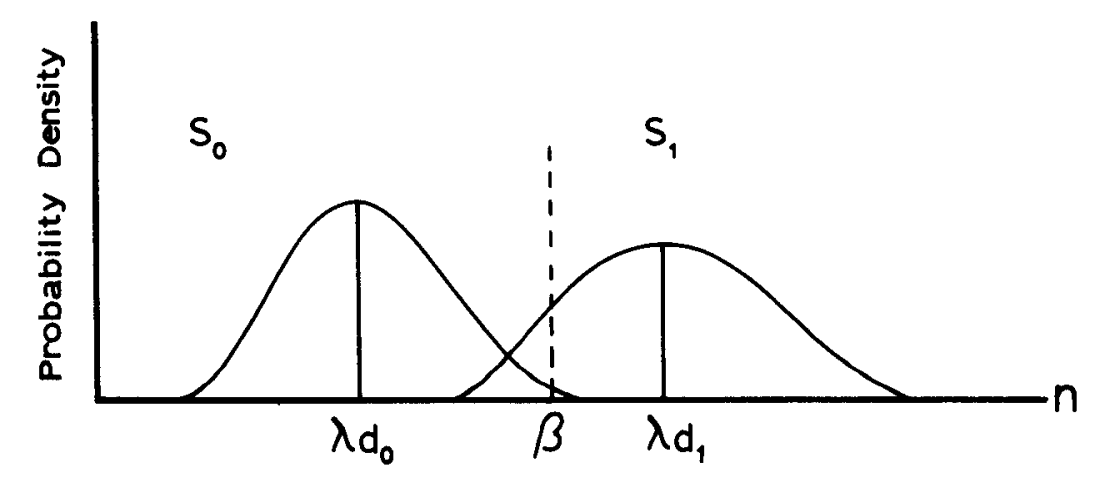

Fig. 1. Distribution of the number of counts conditional upon the stimulus event.

where the constant $\lambda$ represents the rate of firing of the pulse source. Equation 1 describes the Poisson distribution, which for large $\lambda d_{i}$ is closely approximated by a Gaussian distribution with expected value equal to $\lambda \mathrm{d}_{\mathrm{i}}$ and variance also equal to $\lambda \mathrm{d}_{\mathrm{j}}$. Note that the expected value of the perceived or psychological duration of a stimulus is directly proportional to its actual duration. The O's decision problem in a duration discrimination task involving the presentation of one of two possible stimuli on each trial is illustrated in Fig. 1, which represents two overlapping Gaussian distribution of counts. The distribution with expected value $\lambda \mathrm{d}_{0}$ represents the distribution of counts on $S_{0}$ trials; the distribution with expected value $\lambda \mathrm{d}_{1}$ represents the distribution of counts on $S_{1}$ trials. The $O$ is assumed to adopt a criterion number of counts, $\beta$, and to make an $A_{1}$ response only if the observed number of counts exceeds $\beta$.

From Fig. 1 it can be seen that the probability of an $A_{1}$ response given an $S_{1}$ 
stimulus, $P\left(A_{1} \mid S_{1}\right)$, is the area to the right of $\beta$ under the $S_{1}$ distribution; similarly, $P\left(A_{1} \mid S_{0}\right)$, is the area to the right of $\beta$ under the $S_{0}$ distribution. The possible combinations of $P\left(A_{1} \mid S_{1}\right)$ and $P\left(A_{1} \mid S_{0}\right)$ available to the $O$ through variations in his decision criterion are his operating characteristic $(O C)$, which can be specified by two parameters, $d^{\prime}$ and $r$, in the following manner:

$$
d^{\prime}=Z\left(A_{1} \mid S_{0}\right)-1 / r Z\left(A_{1} \mid S_{2}\right),
$$

where $r$ represents the ratio of the standard deviation of the $S_{0}$ distribution to the standard deviation of the $S_{1}$ distribution,

$$
r=\frac{d_{0}^{1 / 2}}{d_{1}^{1 / 2}},
$$

and $Z\left(A_{1} \mid S_{0}\right)$ is that value of a normal deviate which is exceeded with probability $P\left(A_{1} \mid S_{0}\right)$, and $Z\left(A_{1} \mid S_{1}\right)$ is a similar transformation of $P\left(A_{1} \mid S_{1}\right)$. Note that $d^{\prime}$, which is referred to as the discriminability measure, is the difference between the expected values of the two counting distributions expressed in standard deviation units of the $S_{0}$ distribution. Thus,

$$
\mathrm{d}^{\prime}=\frac{\lambda^{1 / 2} \Delta \mathrm{d}}{\mathrm{d}_{0}{ }^{1 / 2}}
$$

where

$$
\Delta \mathrm{d}=\mathrm{d}_{1}-\mathrm{d}_{0} .
$$

Two implications of this model are apparent from Eq. 4. For a fixed value of $d_{0}, d^{\prime}$ should increase as a zero intercept, linear function of $\Delta d$, and for a fixed value of $\Delta \mathrm{d}, \mathrm{d}^{\prime}$ should decrease as a power function of $d_{0}$.

Creelman (1962) has reported data from a two-interval forced-choice discrimination task. On each trial two auditory stimuli which differed in duration were presented in succession, and the $\mathrm{O}$ had to indicate which was longer. On some proportion of the trials, the longer stimulus was presented first; on the remaining trials, the shorter stimulus was presented first. The study was quite extensive and, under some conditions, the model appeared to provide a reasonable interpretation of the data.

The present series of four experiments provide data from a visual duration discrimination task involving the presentation of one of two possible flash durations on each trial. The data are relevant to determining whether an $\mathrm{O}$, when asked to discriminate between brief light flashes of different durations, bases his discriminations on the temporal information available in the stimuli or on the apparent brightness of the stimuli. Furthermore, the data provide a test of Creelman's duration discrimination model for visıal stimuli.

\section{APPARATUS}

The same apparatus was used in the four experiments. The $O$ was seated in a chair in a dark room, with his face placed against the rubber mask attached to a Scientific Prototype tachistoscope (Model 320GB), and viewed the stimuli binocularly. Four small fixation points, 1 in. from each other and arranged in a diamond shape, were visible in an otherwise dark field throughout the session. The stimulus was presented in the center of the four fixation points and consisted of a $1 / 2$-in. square patch of light subtending a visual angle of $.6 \mathrm{deg}$. Luminance was measured at the center of the stimulus by a 150 UB Photo Research Corporation photometer, and the timing of the stimulus presentations was electronically controlled. The $\mathrm{O}$ indicated his response by pressing an appropriate pushbutton located on the arm of his chair.

\section{EXPERIMENT 1}

\section{Procedure}

Three Os participated in this experiment. Each trial began with a $1-\mathrm{sec}$ auditory warning tone. Following a $0.2 \mathrm{sec}$ delay, the stimulus was presented for either $\mathrm{d}_{0}$ msec (an $\mathrm{S}_{0}$ stimulus) or $\mathrm{d}_{0}$ plus $\Delta d$ msec (an $S_{1}$ stimulus). The 0 was then given $3.5 \mathrm{sec}$ to indicate one of four decisions regarding the duration of the stimulus light: short-certain $\left(A_{0, c}\right)$, short-uncertain $\left(A_{0, u}\right)$, long-uncertain $\left(A_{1}, u\right)$, or long-certain $\left(A_{1}, c\right)$. The Os were instructed to base their decisions on the duration of the stimulus and to distribute

\begin{tabular}{|c|c|c|c|c|c|c|c|c|c|c|}
\hline O & $d_{0}$ & $\Delta d$ & $\left(A_{1}, c \mid S_{1}\right)$ & $\left(A_{1}, u \mid S_{1}\right)$ & $\left(A_{0, u} \mid S_{1}\right)$ & $\left(A_{0}, c \mid S_{1}\right)$ & $\left(A_{1, c} \mid S_{0}\right)$ & $\left(A_{1}, u \mid S_{0}\right)$ & $\left(A_{0}, \mathbf{u} \mid S_{0}\right)$ & $\left(A_{0, c} \mid S_{1}\right.$ \\
\hline 1 & $\begin{array}{r}50 \\
100\end{array}$ & $\begin{array}{l}10 \\
20 \\
30 \\
40 \\
50 \\
10 \\
20 \\
30 \\
40 \\
50\end{array}$ & $\begin{array}{r}73 \\
85 \\
86 \\
150 \\
167 \\
53 \\
110 \\
122 \\
156 \\
155\end{array}$ & $\begin{array}{l}169 \\
169 \\
165 \\
185 \\
182 \\
161 \\
152 \\
155 \\
186 \\
194\end{array}$ & $\begin{array}{r}145 \\
124 \\
142 \\
62 \\
45 \\
158 \\
121 \\
108 \\
51 \\
44\end{array}$ & $\begin{array}{r}13 \\
22 \\
7 \\
3 \\
6 \\
28 \\
17 \\
15 \\
7 \\
7\end{array}$ & $\begin{array}{r}32 \\
19 \\
3 \\
3 \\
2 \\
17 \\
25 \\
11 \\
6 \\
6\end{array}$ & $\begin{array}{r}114 \\
63 \\
20 \\
23 \\
14 \\
110 \\
75 \\
40 \\
41 \\
13\end{array}$ & $\begin{array}{l}190 \\
239 \\
263 \\
240 \\
158 \\
227 \\
208 \\
257 \\
243 \\
212\end{array}$ & $\begin{array}{r}64 \\
79 \\
114 \\
134 \\
226 \\
46 \\
92 \\
92 \\
110 \\
169\end{array}$ \\
\hline 2 & $\begin{array}{r}50 \\
100\end{array}$ & $\begin{array}{l}10 \\
20 \\
30 \\
40 \\
50 \\
10 \\
20 \\
30 \\
40 \\
50\end{array}$ & $\begin{array}{l}306 \\
278 \\
295 \\
355 \\
475 \\
213 \\
330 \\
395 \\
468 \\
458\end{array}$ & $\begin{array}{r}83 \\
163 \\
129 \\
175 \\
88 \\
164 \\
121 \\
138 \\
74 \\
78\end{array}$ & $\begin{array}{r}64 \\
113 \\
102 \\
43 \\
21 \\
91 \\
82 \\
50 \\
24 \\
35\end{array}$ & $\begin{array}{r}147 \\
46 \\
74 \\
27 \\
16 \\
132 \\
67 \\
17 \\
34 \\
29\end{array}$ & $\begin{array}{r}190 \\
101 \\
62 \\
28 \\
24 \\
132 \\
140 \\
90 \\
94 \\
72\end{array}$ & $\begin{array}{r}91 \\
148 \\
106 \\
84 \\
29 \\
151 \\
109 \\
118 \\
91 \\
41\end{array}$ & $\begin{array}{r}86 \\
208 \\
164 \\
166 \\
75 \\
109 \\
141 \\
207 \\
99 \\
138\end{array}$ & $\begin{array}{l}233 \\
143 \\
268 \\
322 \\
472 \\
208 \\
210 \\
185 \\
316 \\
349\end{array}$ \\
\hline 3 & 100 & $\begin{array}{l}10 \\
20 \\
30 \\
40 \\
50 \\
10 \\
20 \\
30 \\
40 \\
50\end{array}$ & $\begin{array}{l}136 \\
221 \\
263 \\
310 \\
375 \\
198 \\
251 \\
303 \\
340 \\
357\end{array}$ & $\begin{array}{l}98 \\
82 \\
72 \\
51 \\
17 \\
66 \\
53 \\
53 \\
35 \\
31\end{array}$ & $\begin{array}{r}50 \\
29 \\
35 \\
20 \\
5 \\
38 \\
33 \\
21 \\
17 \\
8\end{array}$ & $\begin{array}{r}116 \\
68 \\
30 \\
19 \\
3 \\
98 \\
63 \\
23 \\
8 \\
4\end{array}$ & $\begin{array}{r}78 \\
81 \\
28 \\
19 \\
4 \\
94 \\
87 \\
28 \\
23 \\
8\end{array}$ & $\begin{array}{l}87 \\
68 \\
46 \\
34 \\
10 \\
59 \\
52 \\
44 \\
33 \\
23\end{array}$ & $\begin{array}{l}\mathbf{4 5} \\
\mathbf{5 5} \\
\mathbf{7 5} \\
\mathbf{5 8} \\
\mathbf{2 1} \\
\mathbf{5 4} \\
\mathbf{5 8} \\
\mathbf{8 8} \\
\mathbf{5 4} \\
\mathbf{5 0}\end{array}$ & $\begin{array}{l}190 \\
196 \\
251 \\
289 \\
365 \\
193 \\
203 \\
240 \\
290 \\
319\end{array}$ \\
\hline
\end{tabular}
their responses equally among the four

Table 1

Frequencies Summarizing Each $O$ 's Performance Under Each of the 10 Conditions in Experiment 1 
Table 2

Estimates of the Conditional Probabilities for Each $O$ Under Each Condition in Experiment 1

\begin{tabular}{|c|c|c|c|c|c|c|c|c|}
\hline $\mathbf{O}$ & $\mathbf{d}_{\mathbf{0}}$ & $\Delta d$ & $P\left(A_{1} \cup A_{0, u} \mid S_{1}\right)$ & $\mathrm{P}\left(\mathrm{A}_{1} \cup \mathrm{A}_{0}, \mathrm{u} \mid \mathrm{S}_{0}\right)$ & $\mathbf{P}\left(\mathbf{A}_{1} \mid \mathbf{S}_{1}\right)$ & $\mathbf{P}\left(\mathbf{A}_{1} \mid \mathbf{S}_{\mathbf{0}}\right)$ & $P\left(A_{1}, c \mid S_{1}\right)$ & $P\left(A_{1}, c \mid S_{0}\right)$ \\
\hline 1 & 100 & $\begin{array}{l}10 \\
20 \\
30 \\
40 \\
50 \\
10 \\
20 \\
30 \\
40 \\
50\end{array}$ & $\begin{array}{l}.967 \\
.945 \\
.982 \\
.992 \\
.985 \\
.930 \\
.957 \\
.962 \\
.982 \\
.982\end{array}$ & $\begin{array}{l}.840 \\
.802 \\
.715 \\
.665 \\
.435 \\
.885 \\
.770 \\
.770 \\
.725 \\
.577\end{array}$ & $\begin{array}{l}.605 \\
.635 \\
.627 \\
.837 \\
.872 \\
.535 \\
.655 \\
.692 \\
.855 \\
.872\end{array}$ & $\begin{array}{l}.365 \\
.205 \\
.057 \\
.065 \\
.040 \\
.317 \\
.250 \\
.127 \\
.117 \\
.047\end{array}$ & $\begin{array}{l}.182 \\
.212 \\
.215 \\
.375 \\
.417 \\
.132 \\
.275 \\
.305 \\
.390 \\
.387\end{array}$ & $\begin{array}{l}.080 \\
.047 \\
.007 \\
.007 \\
.005 \\
.042 \\
.063 \\
.027 \\
.015 \\
.015\end{array}$ \\
\hline 2 & $\begin{array}{r}50 \\
100\end{array}$ & $\begin{array}{l}10 \\
20 \\
30 \\
40 \\
50 \\
10 \\
20 \\
30 \\
40 \\
50\end{array}$ & $\begin{array}{l}.755 \\
.923 \\
.877 \\
.955 \\
.973 \\
.780 \\
.888 \\
.972 \\
.943 \\
.952\end{array}$ & $\begin{array}{l}.612 \\
.762 \\
.553 \\
.463 \\
.213 \\
.653 \\
.650 \\
.692 \\
.473 \\
.418\end{array}$ & $\begin{array}{l}.648 \\
.735 \\
.707 \\
.883 \\
.938 \\
.628 \\
.752 \\
.888 \\
.903 \\
.893\end{array}$ & $\begin{array}{l}.468 \\
.415 \\
.280 \\
.187 \\
.088 \\
.472 \\
.415 \\
.347 \\
.308 \\
.188\end{array}$ & $\begin{array}{l}.510 \\
.463 \\
.492 \\
.592 \\
.792 \\
.355 \\
.550 \\
.658 \\
.780 \\
.763\end{array}$ & $\begin{array}{l}.317 \\
.168 \\
.103 \\
.047 \\
.040 \\
.220 \\
.233 \\
.150 \\
.157 \\
.120\end{array}$ \\
\hline 3 & 100 & $\begin{array}{l}10 \\
20 \\
30 \\
40 \\
50 \\
10 \\
20 \\
30 \\
40 \\
50\end{array}$ & $\begin{array}{l}.710 \\
.830 \\
.925 \\
.952 \\
.992 \\
.755 \\
.842 \\
.942 \\
.980 \\
.990\end{array}$ & $\begin{array}{l}.525 \\
.510 \\
.372 \\
.277 \\
.087 \\
.517 \\
.492 \\
.400 \\
.275 \\
.202\end{array}$ & $\begin{array}{l}.585 \\
.757 \\
.837 \\
.902 \\
.980 \\
.660 \\
.760 \\
.890 \\
.938 \\
.970\end{array}$ & $\begin{array}{l}.412 \\
.372 \\
.185 \\
.132 \\
.035 \\
.382 \\
.347 \\
.180 \\
.140 \\
.077\end{array}$ & $\begin{array}{l}.340 \\
.552 \\
.657 \\
.775 \\
.938 \\
.495 \\
.627 \\
.757 \\
.850 \\
.892\end{array}$ & $\begin{array}{l}.195 \\
.202 \\
.070 \\
.047 \\
.010 \\
.235 \\
.217 \\
.070 \\
.057 \\
.020\end{array}$ \\
\hline
\end{tabular}

Table 3

Estimates of r, Predicted r, and Estimates of $d^{\prime}$ Assuming Unit Slope for Each $O$ Under Each Condition in Experiment 1

\begin{tabular}{|c|c|c|c|c|c|}
\hline \multirow[b]{2}{*}{$\mathrm{O}$} & \multirow[b]{2}{*}{$d_{0}$} & \multirow[b]{2}{*}{$\Delta d$} & \multicolumn{3}{|c|}{ Predicted } \\
\hline & & & $\mathbf{r}$ & $\mathbf{r}$ & $d^{\prime}$ \\
\hline \multirow[t]{10}{*}{1} & \multirow[t]{5}{*}{50} & 10 & 1.148 & .91 & .652 \\
\hline & & 20 & .935 & .84 & .927 \\
\hline & & 30 & .937 & .79 & 1.702 \\
\hline & & 40 & .928 & .74 & 2.203 \\
\hline & & 50 & .969 & .71 & 2.527 \\
\hline & \multirow[t]{5}{*}{100} & 10 & .885 & .95 & .487 \\
\hline & & 20 & 1.015 & .91 & .997 \\
\hline & & 30 & .833 & .88 & 1.363 \\
\hline & & 40 & .849 & .84 & 1.880 \\
\hline & & 50 & .964 & .82 & 2.200 \\
\hline \multirow[t]{10}{*}{2} & \multirow[t]{5}{*}{50} & 10 & .875 & .91 & -455 \\
\hline & & 20 & .910 & .84 & .812 \\
\hline & & 30 & .846 & .79 & 1.127 \\
\hline & & 40 & .938 & .74 & 1.923 \\
\hline & & 50 & 1.200 & .71 & 2.727 \\
\hline & \multirow[t]{5}{*}{100} & 10 & .984 & .95 & .393 \\
\hline & & 20 & .979 & .91 & .863 \\
\hline & & 30 & .971 & .88 & 1.490 \\
\hline & & 40 & .877 & .84 & 1.743 \\
\hline & & 50 & .969 & .82 & 1.963 \\
\hline \multirow[t]{10}{*}{3} & \multirow[t]{5}{*}{50} & 10 & 1.034 & .91 & .458 \\
\hline & & 20 & .989 & .84 & .970 \\
\hline & & 30 & .910 & .79 & 1.843 \\
\hline & & 40 & .838 & .74 & 2.363 \\
\hline & & 50 & .902 & .71 & 3.833 \\
\hline & \multirow[t]{5}{*}{100} & 10 & .924 & .95 & .690 \\
\hline & & 20 & .909 & .91 & 1.073 \\
\hline & & 30 & .704 & .88 & 2.050 \\
\hline & & 40 & 1.027 & .84 & 2.633 \\
\hline & & 50 & .896 & .82 & 3.253 \\
\hline
\end{tabular}

response categories. They did not receive trial-by-trial feedback as to the correctness of their responses.
The intensity of the stimuli was constant at $15 \mathrm{fL}$ throughout the experiment. Both $\mathrm{d}_{0}(50$ or $100 \mathrm{msec})$ and $\Delta \mathrm{d}(10,20,30$, 40 , or $50 \mathrm{msec}$ ) were constant during a particular session but varied between sessions. Each session consisted of five blocks of 100 trials, with a 1 -min rest between blocks. In each block of trials the probability of an $S_{1}$ stimulus, $P\left(S_{1}\right)$, equaled 0.5 .

Each of the 10 experimental conditions was in effect during three sessions for $\mathrm{O} 1$ and $\mathrm{O} 3$, and during four sessions for $\mathrm{O} 2$, the order of conditions being randomly determined with the limitation that each condition be used an equal number of times before any condition was repeated. In an attempt to control warm-up effects and to allow sufficient time for dark adaptation (about $10 \mathrm{~min}$ ), the first block of trials for each session was not included in the final data analysis. Furthermore, in order to provide stable data, the first 10 sessions (1 session under each condition) were not included in the final analysis. In this way data from 800 trials for two of the the Os and from 1,200 trials for the other $O$ were available for each of the 10 experimental conditions.

\section{Theoretical Analysis}

Each $O$ 's performance under each of the 10 experimental conditions can be summarized by eight frequencies: the number of $S_{i}$ trials on which an $A_{j, k}$ response is made, for $i$ and $j$ equal to 1 (long) or 0 (short), and $\mathrm{k}$ equal to $\mathrm{c}$ (certain) or $u$ (uncertain). These frequencies, denoted as $\left(A_{j, k} \mid S_{j}\right)$, are presented in Table 1.

Operating characteristic (OC) curves can be generated from the frequencies presented in Table 1 using the procedure described by Green and Swets (1966, pp. 101-103). Each OC is determined by six conditional probabilities of the form

$$
\begin{aligned}
& P\left(A_{1} \cup A_{0}, u \mid S_{i}\right), \\
& P\left(A_{1} \mid S_{i}\right), \\
& P\left(A_{1, c} \mid S_{i}\right),
\end{aligned}
$$

for $i$ equal to 1 or 0 . Estimates of the six conditional probabilities determining each of the $30 \mathrm{OC}$ curves (three Os and 10 conditions) are presented in Table 2. For each set of three points, the best fitting $\mathrm{OC}$, based on the assumption of underlying Gaussian distributions, was determined using the following procedure. Rearrangement of Eq. 2,

$$
Z\left(A_{1} \mid S_{1}\right)=r Z\left(A_{1} \mid S_{0}\right)-r d^{\prime},
$$

shows that the $\mathrm{OC}$, when plotted on $Z$-coordinates, is a straight line with slope $r$ and $Z\left(A_{1} \mid S_{1}\right)$ - intercept equal to $\mathrm{rd}^{2}$. Values of $Z\left(A_{1} \mid S_{1}\right)$ and $Z\left(A_{1} \mid S_{0}\right)$ were calculated from each $O$ 's performance, and for each condition the best fitting, straight line, $O C$ was determined by minimizing 


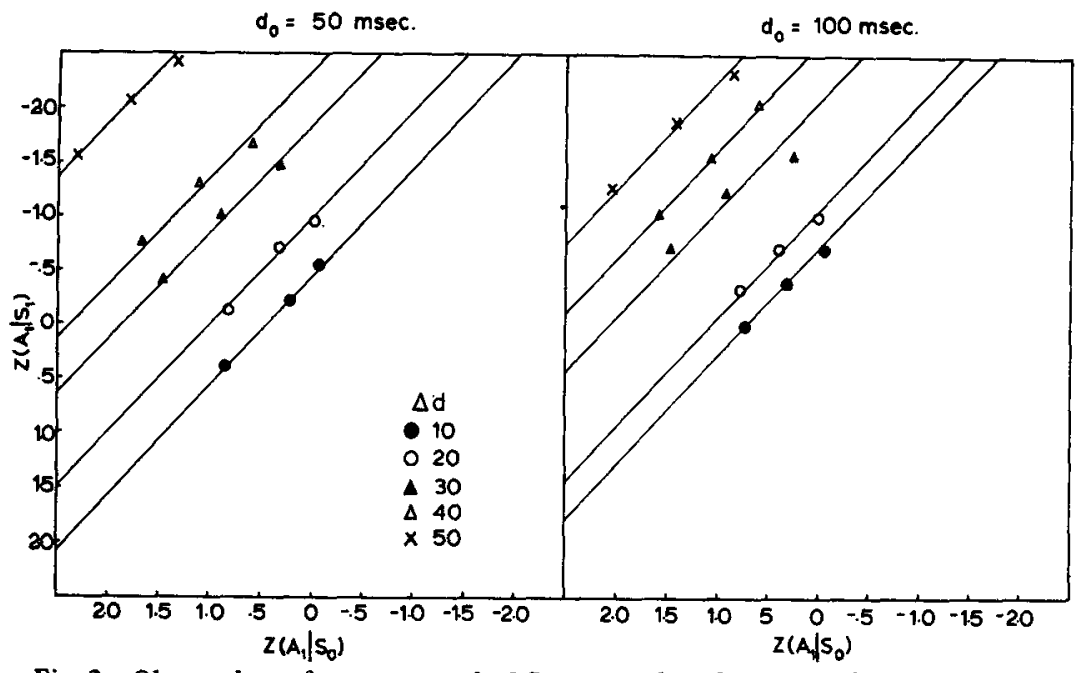

Fig. 2. Observed performance and $O C$ curves based on equal-variance Gaussian distributions for 03 .

the sum of the squared perpendicular discrepancies between the $O$ 's performance and the line. Specifically,

$$
r=\sqrt{\frac{N \Sigma y^{2}-(\Sigma y)^{2}}{N \Sigma x^{2}-(\Sigma x)^{2}}}
$$

and

$$
\mathrm{rd}^{\prime}=\frac{\Sigma \mathrm{y}-\mathrm{r} \Sigma \mathrm{x}}{\mathrm{N}}
$$

where $y=Z\left(A_{1} \mid S_{1}\right), x=Z\left(A_{1} \mid S_{0}\right)$, and $N=3$. Estimates of $r$ for each $O$ under each experimental condition, as well as the value of $\mathrm{I}$ predicted by Eq. 3, are presented in Table 3. It is clear that the estimated values of $\mathrm{I}$ are not related to changes in $\Delta \mathrm{d}$ in the manner specified by the Creelman model. In fact, for large differences in $\Delta d$, the estimated slope is often very close to unity. If the observed deviations from unity are simply the result of sampling error, then a
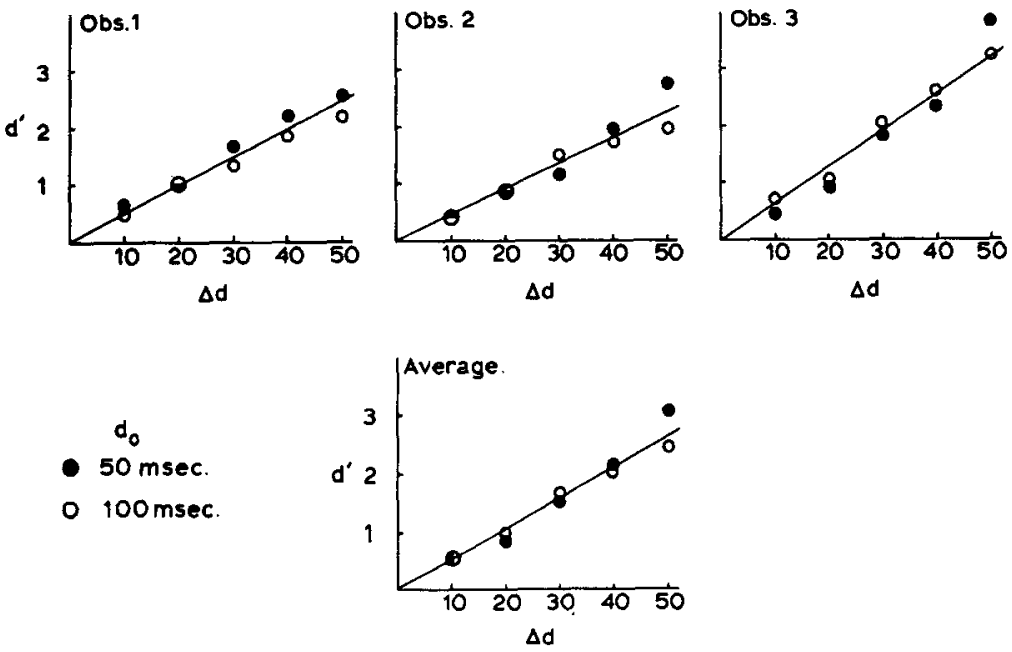

Fig. 3. Estimates of $d^{\prime}$ for each $O$ under each condition in Experiment 1. they do not support the prediction that the variance of the distribution increases systematically with an increase in the physical duration of the stimulus.

The $d^{\prime}$ values assuming unit slope are presented numerically in Table 3 and are plotted as a function of $\Delta \mathrm{d}$ in Fig. 3 . It is of interest to note that although the two values of $\mathrm{d}_{0}$ differed by $50 \mathrm{msec}$, the ability to discriminate a particular difference in duration between the two light flashes is similar for the two values of $\mathrm{d}_{0}$. For each $\mathrm{O}$, a zero-intercept straight line was fitted to the 10 data points and is plotted in Fig. 3. Figure 3 indicates that a linear relationship between $d^{\prime}$ and $\Delta d$ which is independent of the value of $d_{0}$ is an adequate description of each $O$ 's performance. This linear relationship accounts for $0.95,0.92$, and 0.94 of the total variance in $d^{\prime}$, for Os 1,2 , and 3 , respectively.

We shall now present a model for duration discrimination which specifies that discriminability depends only on the difference in duration between the two brief stimuli and is independent of their total durations. Suppose that at some time after the onset of a $d_{i}-m s e c$ stimulus an internal timing process is activated by the stimulus onset and that this internal timing process is the basis for discrimination. The time which elapses between the onset of the stimulus and the beginning of the internal timing process is called the psychological onset time. Similarly, the offset of the stimulus terminates the internal timing process after a time delay referred to as the psychological offset time. Assume further that the psychological onset time and the psychological offset time have uniform distributions, $f_{1}(u)$ and $\mathrm{f}_{2}(\mathrm{u})$, respectively, over an interval of $q$ msec, where $q$ is independent of the duration of the stimulus. That is,

$$
f_{1}(u)=\left\{\begin{array}{l}
1 / q \text { if } 0<u<q \\
0 \text { otherwise }
\end{array}\right.
$$

and

$$
f_{2}(u)=\left\{\begin{array}{l}
1 / q \text { if } d_{i}<u<d_{i}+q \\
0 \text { otherwise }
\end{array}\right.
$$

Furthermore, $E\left(U_{1}\right)=q / 2$, and $E\left(U_{2}\right)=$ $\mathrm{d}_{\mathrm{i}}+\mathrm{q} / 2$, where $\mathrm{E}\left(\mathrm{U}_{1}\right)$ denotes the expected value of the onset random variable, $\mathrm{U}_{1}$, and $\mathrm{E}\left(\mathrm{U}_{2}\right)$ denotes the expected value of the offset random variable, $\mathrm{U}_{2}$. It can be shown (Parzen, 1960) that the distribution of durations of the internal timing process, denoted as $g\left(u^{\prime}\right)$, which is associated with $\mathrm{d}_{\mathrm{i}}-\mathrm{msec}$ stimulus is 


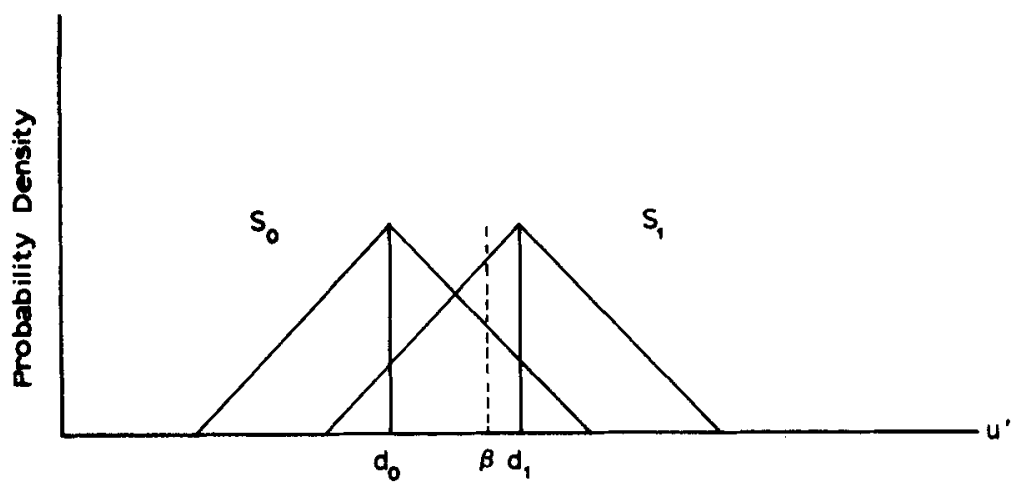

Fig. 4. Distribution of psychological durations conditional upon the stimulus event.

$$
g\left(u^{\prime}\right)=\int f_{2}(u) f_{1}\left(u-u^{\prime}\right) d u
$$

If it is assumed that $U_{1}$ is independent of $\mathrm{U}_{2}$, then integrating Eq. 5 yields

$$
g\left(u^{\prime}\right)=\left\{\begin{array}{l}
\frac{q+d_{i}-u^{\prime}}{q^{2}} \text { if } d_{i}<u^{\prime}<d_{i}+q \\
\frac{q-d_{i}+u^{\prime}}{q^{2}} \text { if } d_{i}-q<u^{\prime}<d_{i} \\
0 \text { otherwise }
\end{array}\right.
$$

Thus, the distribution of durations of the internal timing process, which we shall also refer to as the psychological durations, is triangular over an interval of $2 q \mathrm{msec}$, and the expected value of the psychological duration random variable, $\mathrm{U}^{\prime}$, is

$$
\begin{aligned}
\mathrm{E}\left(\mathrm{U}^{\prime}\right) & =\mathrm{E}\left(\mathrm{U}_{2}\right)-\mathrm{E}\left(\mathrm{U}_{1}\right) \\
& =\mathrm{d}_{\mathrm{i}} .
\end{aligned}
$$

The O's decision problem in a duration discrimination task involving the presentation of one of two possible stimuli on each trial is illustrated in Fig. 4, which represents two overlapping triangular distributions of psychological durations. The distribution with expected value $d_{0}$ represents the distribution on $S_{0}$ trials; the distribution with expected value $d_{1}$ represents the distribution on $S_{1}$ trials. The $O$ is assumed to adopt a criterion value of psychological duration, $\beta$, and to make an $A_{1}$ response only if $u^{\prime}$ exceeds $\beta$. The O's $O C$ can be specified by one parameter, $d_{q}$, in the following manner:

$$
d_{q}=Q\left(A_{1} \mid S_{0}\right)-Q\left(A_{1} \mid S_{1}\right),
$$

where $Q\left(A_{1} \mid S_{0}\right)$ is the distance in $q$ units from the mean of the $S_{0}$ distribution to the criterion, and $Q\left(A_{1} \mid S_{1}\right)$ is the distance in $q$ units from the mean of the $S_{1}$ distribution to the criterion. Thus, $Q\left(A_{1} \mid S_{i}\right)$ is that value of a psychological duration, expressed in $q$ units, which is

\begin{tabular}{|c|c|c|c|c|c|}
\hline 0 & $\mathbf{q}$ & $\mathbf{d}_{0}$ & $\Delta d$ & Slope & $\mathbf{d}_{\mathbf{g}}$ \\
\hline \multirow[t]{10}{*}{1} & 51.28 & 50 & 10 & 1.106 & .26 \\
\hline & & & 20 & .940 & .38 \\
\hline & & & 30 & .974 & .63 \\
\hline & & & 40 & .907 & .83 \\
\hline & & & 50 & 1.073 & .97 \\
\hline & & 100 & 10 & .899 & .19 \\
\hline & & & 20 & .993 & .41 \\
\hline & & & 30 & .833 & .56 \\
\hline & & & 40 & .835 & .75 \\
\hline & & & 50 & .968 & .87 \\
\hline \multirow[t]{10}{*}{2} & 52.08 & 50 & 10 & .911 & .19 \\
\hline & & & 20 & .889 & .35 \\
\hline & & & 30 & .842 & .49 \\
\hline & & & 40 & .944 & .81 \\
\hline & & & 50 & 1.088 & 1.14 \\
\hline & & 100 & 10 & .986 & .17 \\
\hline & & & 20 & .998 & .38 \\
\hline & & & 30 & .884 & .62 \\
\hline & & & 40 & .808 & .75 \\
\hline & & & 50 & .879 & .84 \\
\hline \multirow[t]{10}{*}{3} & 37.59 & 50 & 10 & 1.021 & .20 \\
\hline & & & 20 & 1.000 & .42 \\
\hline & & & 30 & .914 & .79 \\
\hline & & & 40 & .836 & 1.01 \\
\hline & & & 50 & .784 & 1.50 \\
\hline & & 100 & 10 & .932 & .30 \\
\hline & & & 20 & .904 & .47 \\
\hline & & & 30 & .705 & .88 \\
\hline & & & 40 & .838 & 1.10 \\
\hline & & & 50 & .800 & 1.31 \\
\hline
\end{tabular}
exceeded with probability $P\left(A_{1} \mid S_{i}\right)$. Note
Table 4

Estimates of Slope, of $d_{a}$ Assuming Unit Slope, and of $q$ for Each $O$ in Experiment 1

In general, these lines closely approximate the observed performance, suggesting that the psychological durations evoked by a brief flash of light can be represented by a triangular distribution with a base which is independent of the duration of the light flash. The $d_{q}$ values assuming unit slope are presented numerically in Table 4 and are plotted as a function of $\Delta d$ in Fig. 6. For plotted on Q-coordinates in Fig. 5 for 03

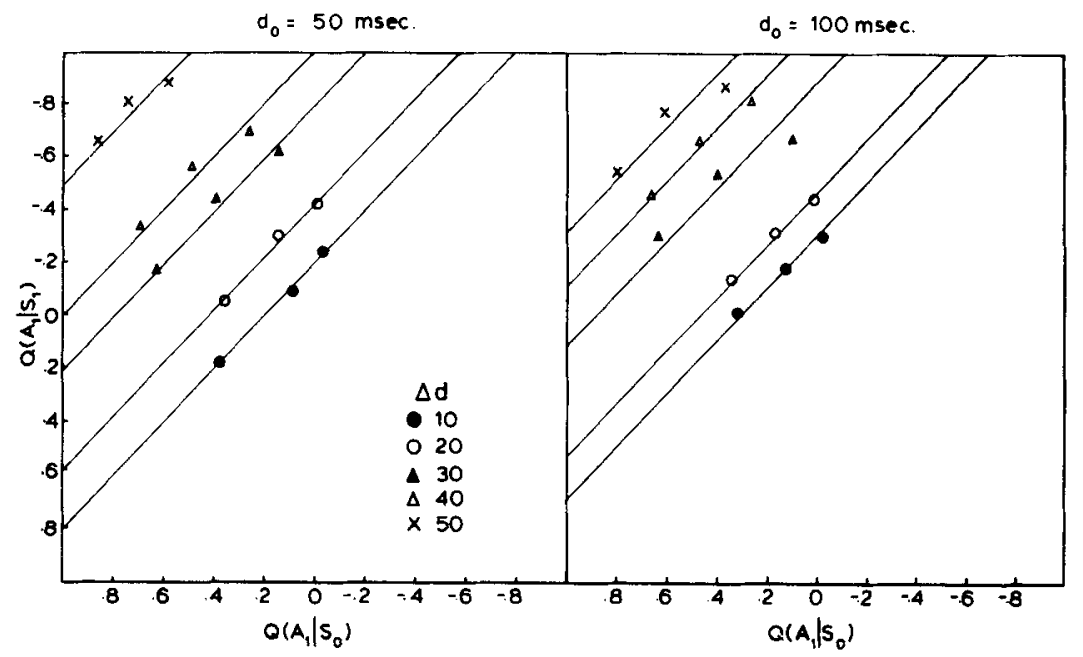

Fig. 5. Observed performance and $O C$ curves based on equal base triangular distributions for $\mathrm{O} 3$. 

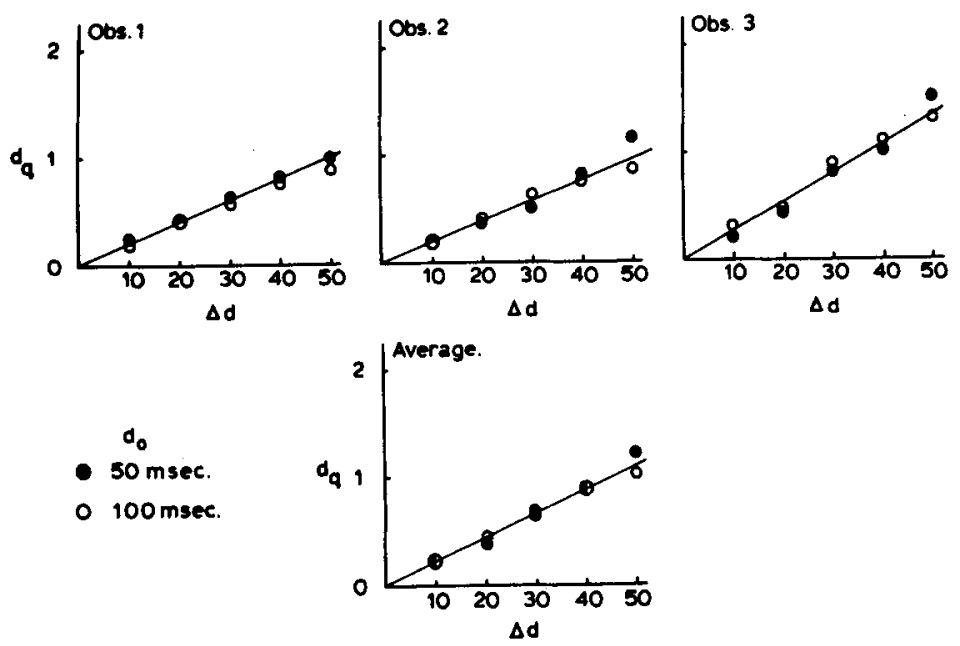

Fig. 6. Estimates of $d_{q}$ for each $O$ under each condition in Experiment 1. each $\mathrm{O}$ a zero-intercept straight line was fitted to the 10 data points and is plotted in Fig. 6. This linear relationship accounts for $0.97,0.93$, and 0.97 of the total variance in $d_{q}$, for Os 1,2 , and 3 , respectively. An estimate of $q$ was obtained for each $O$ from the siope of his function and these estimates are presented in Table 4. We shall discuss a plausible interpretation of $q$ after presenting the data from the other three experiments.

\section{EXPERIMENT 2}

Six new Os performed in an experimental situation similar to that of Experiment 1, except that there were only two response categories and feedback was provided on each trial.

\section{Procedure}

The procedure was similar to that described for Experiment 1 except that the 0 was given $2.0 \mathrm{sec}$ on each trial to indicate one of two choices regarding the duration of the stimulus light: short $\left(A_{0}\right)$ or long $\left(A_{1}\right)$. Furthermore, the 0 was informed, by means of an auditory signal, as to the correctness of his response on each trial. Two values of $d_{0}$ (50 or $100 \mathrm{msec})$ and four values of $\Delta d(10,20$, 30 , or $40 \mathrm{msec}$ ) were used. For each $O$, data from 1,600 trials were available for each of the eight experimental conditions.

\section{Theoretical Analysis}

Each O's performance under each of the eight experimental conditions can be summarized by estimates of two conditional probabilities $P\left(A_{1} \mid S_{1}\right)$ and $\mathbf{P}\left(\mathrm{A}_{1} \mid \mathrm{S}_{0}\right)$, and these estimates are presented in Table 5, along with the estimated $d_{q}$ values (Eq. 7). These estimates of $d_{q}$ are plotted as a function of $\Delta d$ in Fig. 7. For each O, a zero-intercept straight line was fitted to the eight data points and is plotted in Fig. 7. For three of the $O s(0 s 4,5$, and 6$), d_{q}$ appears to be independent of the value of $\mathrm{d}_{0}$ and to increase as a zero-intercept linear function of $\Delta \mathrm{d}$. Two of the other Os (Os 7 and 8) display greater discriminability when $d_{0}$ equals $50 \mathrm{msec}$, while the remaining $O$ (0 9) displays greater discriminability when $d_{0}$ equals $100 \mathrm{msec}$. Thus, these results, while supporting the findings of Experiment 1, also suggest that there may be individual differences in the manner in which Os judge the duration of brief flashes of light. An estimate of $q$ was obtained for each $\mathrm{O}$ from the slope of his function and these estimates are presented in Table 5.

\section{EXPERIMENT 3}

Experiment 3 was designed to investigate whether the Os were basing their discriminations on the temporal information available in the stimuli or on the apparent brightness of the stimuli.

\section{Procedure}

The procedure was similar to that described for Experiment 2 and five of the six Os from that experiment (Os $5,6,7,8$, and 9) participated. One value of $d_{0}$ (100 msec) and one value of $\Delta d(20 \mathrm{msec})$ were used. Whereas in the previous experiments the luminance of the two stimuli was the same $(15 \mathrm{fL})$, in this experiment $S_{0}$ was always $15 \mathrm{fL}$, while the luminance of $S_{1}$ was varied between sessions $(15,13$, or $11 \mathrm{fL})$. Thus, during a session the difference in luminance between the two stimuli, $\Delta \mathrm{I}$, could be 0,2 , or $4 \mathrm{fL}$. The $\mathrm{Os}$ were not informed that the luminance of $S_{1}$ would vary between sessions. For each $O$ data from 1,200 trials were available for each of the three experimental conditions.

\section{Theoretical Analysis}

Estimates of $P\left(A_{1} \mid S_{1}\right), P\left(A_{1} \mid S_{0}\right)$, and $d_{q}$ are presented in Table 6 for each $O$. These estimates of $d_{q}$ are plotted as a function of $\Delta \mathrm{I}$ in Fig. 8 . The variation in $d_{q}$ is quite small, and the form of the
Table 5

Estimates of $P\left(A_{1} \mid S_{1}\right), P\left(A_{1} \mid S_{0}\right), d_{q}$, and $q$ for Each $O$ Under Each Condition in Experiment 2

\begin{tabular}{|c|c|c|c|c|c|c|c|c|}
\hline \multirow[b]{2}{*}{ O } & \multirow[b]{2}{*}{$\mathbf{q}$} & \multirow[b]{2}{*}{$\Delta \mathbf{d}$} & \multicolumn{3}{|c|}{$d_{0}=50$} & \multicolumn{3}{|c|}{$d_{0}=100$} \\
\hline & & & $\mathbf{P}\left(\mathbf{A}_{1} \mid \mathbf{S}_{1}\right)$ & $P\left(A_{1} \mid S_{0}\right)$ & $\mathbf{d}_{\mathbf{q}}$ & $P\left(A_{1} \mid S_{1}\right)$ & $P\left(A_{1} \mid S_{0}\right)$ & $\mathrm{d}_{\mathrm{q}}$ \\
\hline 4 & 22.96 & $\begin{array}{l}10 \\
20 \\
30 \\
40\end{array}$ & $\begin{array}{l}.725 \\
.862 \\
.920 \\
.975\end{array}$ & $\begin{array}{l}.327 \\
.142 \\
.097 \\
.010\end{array}$ & $\begin{array}{r}.45 \\
.94 \\
1.16 \\
1.63\end{array}$ & $\begin{array}{l}.728 \\
.875 \\
.948 \\
.992\end{array}$ & $\begin{array}{r}.295 \\
.153 \\
.047 \\
.010\end{array}$ & $\begin{array}{r}.49 \\
.95 \\
1.37 \\
1.72\end{array}$ \\
\hline 5 & 46.08 & $\begin{array}{l}10 \\
20 \\
30 \\
40\end{array}$ & $\begin{array}{l}.563 \\
.635 \\
.712 \\
.848\end{array}$ & $\begin{array}{l}.387 \\
.268 \\
.160 \\
.143\end{array}$ & $\begin{array}{l}.18 \\
.41 \\
.67 \\
.91\end{array}$ & $\begin{array}{l}.508 \\
.683 \\
.738 \\
.848\end{array}$ & $\begin{array}{l}.312 \\
.345 \\
.187 \\
.143\end{array}$ & $\begin{array}{l}.22 \\
.37 \\
.67 \\
.91\end{array}$ \\
\hline 6 & 23.95 & $\begin{array}{l}10 \\
20 \\
30 \\
40\end{array}$ & $\begin{array}{l}.782 \\
.877 \\
.970 \\
.980\end{array}$ & $\begin{array}{l}.327 \\
.210 \\
.053 \\
.033\end{array}$ & $\begin{array}{r}.53 \\
.85 \\
1.42 \\
1.54\end{array}$ & $\begin{array}{l}.732 \\
.885 \\
.947 \\
.978\end{array}$ & $\begin{array}{l}.378 \\
.196 \\
.123 \\
.028\end{array}$ & $\begin{array}{r}.40 \\
.89 \\
1.17 \\
1.55\end{array}$ \\
\hline 7 & 26.25 & $\begin{array}{l}10 \\
20 \\
30 \\
40\end{array}$ & $\begin{array}{l}.663 \\
.838 \\
.947 \\
.970\end{array}$ & $\begin{array}{l}.343 \\
.145 \\
.062 \\
.020\end{array}$ & $\begin{array}{r}.35 \\
.89 \\
1.32 \\
1.55\end{array}$ & $\begin{array}{l}.697 \\
.813 \\
.910 \\
.943\end{array}$ & $\begin{array}{r}.392 \\
.195 \\
.122 \\
.053\end{array}$ & $\begin{array}{r}.33 \\
.77 \\
1.08 \\
1.33\end{array}$ \\
\hline 8 & 22.12 & $\begin{array}{l}10 \\
20 \\
30 \\
40\end{array}$ & $\begin{array}{l}.690 \\
.898 \\
.973 \\
.998\end{array}$ & $\begin{array}{l}.275 \\
.082 \\
.015 \\
.002\end{array}$ & $\begin{array}{r}.47 \\
1.15 \\
1.60 \\
1.88\end{array}$ & $\begin{array}{l}.800 \\
.883 \\
.903 \\
.972\end{array}$ & $\begin{array}{l}.380 \\
.190 \\
.107 \\
.047\end{array}$ & $\begin{array}{r}.50 \\
.90 \\
1.10 \\
1.45\end{array}$ \\
\hline 9 & 26.46 & $\begin{array}{l}10 \\
20 \\
30 \\
40\end{array}$ & $\begin{array}{l}.698 \\
.780 \\
.897 \\
.910\end{array}$ & $\begin{array}{l}.380 \\
.168 \\
.112 \\
.037\end{array}$ & $\begin{array}{r}.35 \\
.76 \\
1.08 \\
1.30\end{array}$ & $\begin{array}{l}.702 \\
.848 \\
.937 \\
.970 \\
\end{array}$ & $\begin{array}{r}.303 \\
.160 \\
.065 \\
.043 \\
\end{array}$ & $\begin{array}{r}.45 \\
.88 \\
1.29 \\
1.46 \\
\end{array}$ \\
\hline
\end{tabular}



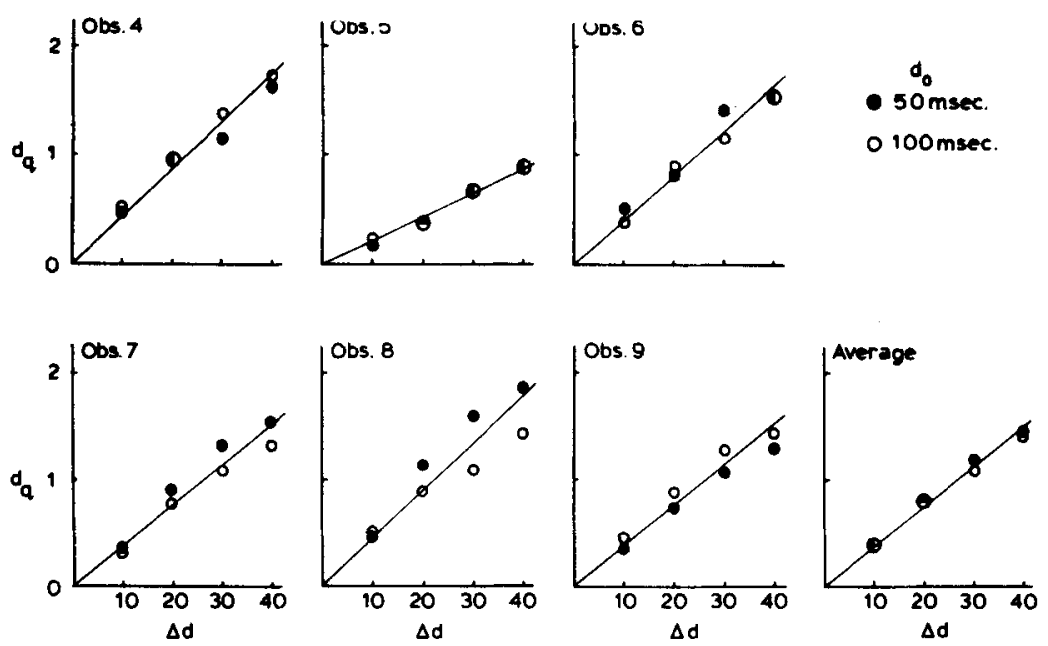

Fig. 7. Estimates of $d_{q}$ for each $O$ under each condition in Experiment 2. function is not consistent over the five Os. On the average, changes in $\Delta \mathrm{I}$ have little effect on an O's ability to discriminate a difference in duration. Furthermore, the data imply that the three Os (Os 7, 8, and 9), whose ability to discriminate a given duration was dependent on the value of $S_{0}$, were not basing their discriminations on the apparent brightnesses of the flashes.

\section{EXPERIMENT 4}

This experiment was designed to investigate whether or not the differences in luminance between $S_{0}$ and $S_{1}$ in the previous experiment were large enough to be discriminated.

\section{Procedure}

Os $5,7,8$, and 9 participated in this experiment. One value of $d_{0}(100 \mathrm{msec})$, one value of $\Delta d(0 \mathrm{msec})$, and three values of $\Delta I(0,2$, or $4 \mathrm{fL})$ were used. The 0 was informed that the stimuli differed only in brightness and that he should make an $\mathbf{A}_{0}$ response when he thought the stimulus was bright and an $A_{1}$ response when he thought it was dim. For each $O$, data from 800 trials were available for each of the three experimental conditions.

\section{Results}

Since we have not presented a model to represent the manner in which an $\mathrm{O}$ discriminates a difference in luminance between two stimuli, we will consider the relationship between the probability of a correct response, $\mathrm{P}(\mathrm{C})$, and changes in the luminance of $S_{t}$, where

$\mathrm{P}(\mathrm{C})$

$=P\left(S_{1}\right) P\left(A_{1} \mid S_{1}\right)+P\left(S_{0}\right)\left[1-P\left(A_{1} \mid S_{0}\right)\right]$.

Estimates of $P\left(A_{1} \mid S_{1}\right), P\left(A_{1} \mid S_{0}\right)$, and $P(C)$ are presented in Table 7 for each O. It is clear that Os are able to discriminate the differences in luminance used in Experiment 3.

\section{DISCUSSION}

In summary, the $O C$ curves generated from the data from Experiment 1 suggest that the psychological durations evoked by a brief light flash can be approximated by a triangular distribution with a base which is independent of the duration of the flash. Secondly, the data from Experiment 1 and Experiment 2 indicate that for six of the nine $\mathrm{Os}_{\mathrm{q}}$, a measure of an O's ability to discriminate a difference in duration
Table 6

Estimates of $P\left(A_{1} \mid S_{1}\right), P\left(A_{1} \mid S_{0}\right)$, and $d_{q}$ for Each $O$ Under Each Condition in Experiment 3

\begin{tabular}{ccccc}
\hline 0 & $\Delta I$ & \multicolumn{1}{c}{$P\left(A_{1} \mid S_{1}\right)$} & $P\left(A_{1} \mid S_{0}\right)$ & $d_{q}$ \\
\hline 5 & 0 & .665 & .260 & .46 \\
& 2 & .732 & .258 & .56 \\
& 4 & .686 & .304 & .43 \\
6 & 0 & .891 & .222 & .86 \\
& 2 & .862 & .264 & .75 \\
& 4 & .855 & .167 & .88 \\
7 & 0 & .836 & .126 & .93 \\
& 2 & .861 & .096 & 1.03 \\
& 4 & .882 & .069 & 1.14 \\
8 & 0 & .867 & .190 & .86 \\
& 2 & .845 & .198 & .81 \\
& 4 & .852 & .172 & .87 \\
9 & 0 & .884 & .092 & 1.09 \\
& 2 & .912 & .074 & 1.22 \\
& 4 & .889 & .075 & 1.14 \\
\hline
\end{tabular}

between two brief flashes of light, is directly proportional to the duration difference between the two stimuli and is independent of the stimulus duration, at least for the range of brief durations used. Lastly, the data from Experiments 3 and 4 indicate that discriminable changes in the luminance of the longer flash have little effect on an O's duration-discrimination performance. Thus, when Os are asked to discriminate between flashes of different durations, for durations for which Bloch's law has been shown to hold, their discriminations are frequently made on the temporal information available in the two
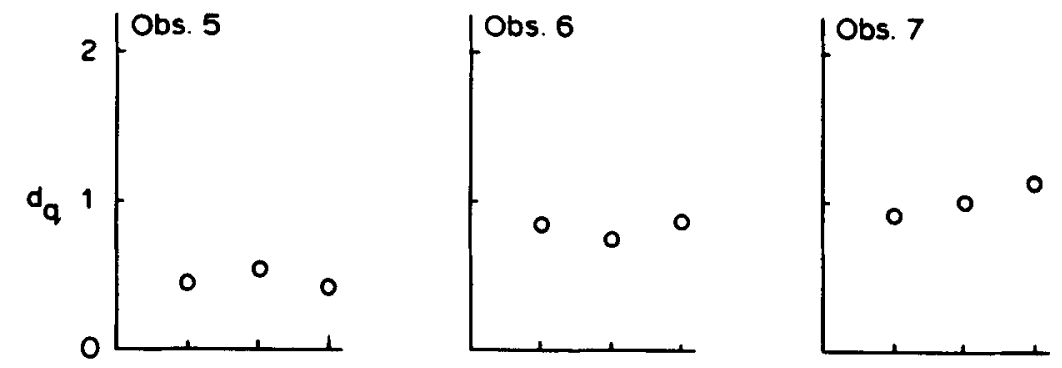

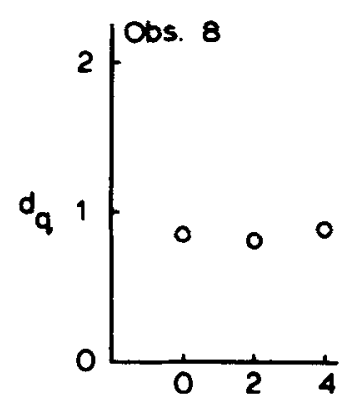

$\Delta I$
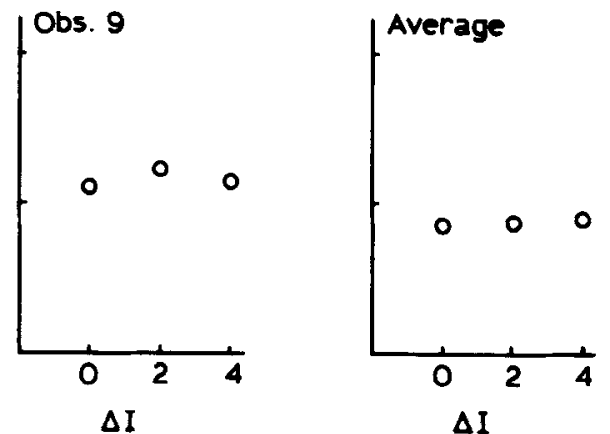

Fig. 8. Estimates of $d_{q}$ for each 0 under each condition in Experiment 3. 
Table 7

Estimates of $P\left(A_{1} \mid S_{1}\right), P\left(A_{1} \mid S_{0}\right)$, and $P(C)$ for Each $O$ Under Each Condition in Experiment 4

\begin{tabular}{lcccc}
\hline 0 & $\Delta I$ & $P\left(A_{1} \mid S_{1}\right)$ & $P\left(A_{1} \mid S_{0}\right)$ & $P(C)$ \\
\hline 5 & 0 & .35 & .34 & .50 \\
& 2 & .40 & .37 & .52 \\
& 4 & .47 & .27 & .60 \\
7 & 0 & .40 & .40 & .50 \\
& 2 & .46 & .23 & .62 \\
& 4 & .71 & .14 & .78 \\
8 & 0 & .47 & .41 & .53 \\
& 2 & .63 & .34 & .64 \\
& 4 & .80 & .13 & .84 \\
9 & 0 & .41 & .35 & .53 \\
& 2 & .59 & .25 & .67 \\
& 4 & .75 & .05 & .85 \\
\hline
\end{tabular}

stimuli rather than on their apparent brightness.

Baron (1969) has also suggested that the time between the occurrence of a stimulus and its perception is variable from trial to trial. However, he has assumed that the distribution of these times is Gaussian. A Gaussian assumption about psychological onset and offset time would result in a Gaussian rather than a triangular distribution of psychological durations. The form of the OC curve has often been used (see Green \& Swets, 1966) to distinguish between different underlying distributions of sensory states. It is clear from a comparison of Fig. 2 with Fig. 5 that the $O C$ curves generated from an assumption of uniform distributions provide as good a representation of the observed data as those generated from an assumption of Gaussian distributions. Our preference for assuming uniform distributions of onset and offet times over Gaussian distributions is related to the estimates of $q$ that we have obtained.

Kristofferson (1967a) has postulated an "internal clock" which generates a succession of equally spaced points in time which are independent of the presentation of an external stimulus event. These time points occur at the rate of one every $q \mathrm{msec}$, and under normal conditions the rate is assumed to be constant for any $O$. He has presented data which support the assumptions that the time points are the instants at which attention can switch from one input channel to another and that they determine when information which is in one stage or state of central processing can be transferred into a subsequent stage. Estimates of $q$ have been obtained from the performance of individual $O s$ in successiveness discrimination tasks and in simple and choice reaction-time situations. These estimates are usually around $50 \mathrm{msec}$ (Krist offerson, $1967 \mathrm{a}, \mathrm{b}$ ), although recently data has been reported (Kristofferson, 1969) which suggest a quantum size of $25 \mathrm{msec}$. It is of interest that the estimates of $\mathrm{q}$ obtained from the performance of the $O s$ in the present experiments are very similar to those estimated from successiveness discrimination and reaction-time performance. Of course, further research is needed to determine whether these similarities are of theoretical significance or simply coincidental.

It should be noted that the model of duration discrimination that is developed in this paper states that variability in psychological duration is caused by a quantal process but that psychological duration itself is not quantized but is, on the contrary, a continuous variable.

\section{REFERENCES}

AIBA, T. S., \& STEVENS, S. S. Relation of brightness to duration and luminance under light- and dark-adaption. Vision Research, $1964,4,391-401$.

ANGLIN, J. M., \& MANSFIELD, J. W. On the brightness of short and long flashes. Perception \& Psy chophysics, 1968, 4, 161-162.

BARON, J. Temporal ROC curves and the psychological moment. Psychonomic Science, 1969, 15, 299-300.

CREELMAN, C. D. Human discrimination of auditory duration. Journal of the Acoustical Society of America, 1962, 34, 582-593.

GREEN, D. M., \& SWETS, J. A. Signal detection theory and psychophysics. New York: Wiley, 1966.

KRISTOFFERSON, A. B. Attention and psychophysical time. Acta Psychologica, 1967a, 27, 93-100.

KRISTOFFERSON, A. B. Successiveness discrimination as a two-state quantal process. Science, 1967b, 158, 1337-1339.

KRISTOFFERSON, A. B. Sensory attention. Psychology series, McMaster University, Technical Report No. 36, 1969.

PARZEN, E. Modern probability theory and its applications. New York: Wiley, 1960.

RAAB , D. Magnitude estimation of the brightness of brief foveal stimuli. Science, $1962,135,42-43$.

STEVENS, J. C., \& HALL, J. W. Brightness and loudness as functions of stimulus duration. Perception \& Psychophysics, 1966, 1, 319-327.

STEVENS, S. S. Duration, luminance, and the brightness exponent. Perception \& Psychophysics, 1966, 1, 96-100.

WICKE, J. D., DONCHIN, E., \& LINDSLEY, D. B. Visual evoked potentials as a function of flash luminance and duration. Science, 1964, $146,83-85$.

(Acrepted for publication September 11, 1970.) 